\title{
SOBRE LA AUTONOMÍA DE LA ACCIÓN \\ INDEMNIZATORIA. REFLEXIONES A PROPÓSITO \\ DEL CASO "ZORIN CON CÍA. SIDERÚRGICA HUACHIPATO 2012"*
}

ABOUt THE AUTONOMY OF TORTS. THOUGHTS ON CASE "ZORIN VS.

SIDERÚRGICA HUACHIPATO COMPANY OF 2012"

SUR L'AUTONOMIE DE L'ACTION DE DOMMAGES-INTÊRETS.

Rérlexions à propos du cas "Zorin aVEC CIA. ACIER

HUACHIPATO 2012"

Hugo Cádenas Villarroel ${ }^{* *}$

Debido a la interpretación que se ha hecho de la norma contenida en el artículo 1489 del Código Civil (CC), en el ordenamiento jurídico chileno se ha negado la posibilidad de que el acreedor de un contrato incumplido pueda demandar la indemnización de perjuicios sin pedir al mismo tiempo el cumplimiento forzado o la resolución del mismo. No obstante que la regla se refiere en términos generales al contrato, el problema se circunscribe a las obligaciones de dar y, en menor medida, a las de no hacer (por su baja incidencia). Respecto de las obligaciones de hacer, no obstante la solución contraria y más bien irreflexiva de algunos fallos históricos ${ }^{1}$, la norma contenida en el artículo 1553 del CC faculta al acreedor para que opte -junto con la indemnización de la mora-, entre el cumplimiento forzoso, la ejecución por un tercero a expensas del deudor, y la indemnización compensatoria de perjuicios ${ }^{2}$.

"Quinto Juzgado Civil de Santiago, “Zorin S.A con Compañía Siderúrgica Huachipato”, 30 de noviembre de 2009, Rol No 20400-2008; Corte de Apelaciones de Concepción, 11 de enero de 2012, Rol No 5332010; Corte Suprema, 31 de octubre de 2012, Rol No 3325-2012.

**Abogado. Doctor en Derecho por la Pontificia Universidad Católica de Chile. Profesor de Derecho Civil de la Facultad de Derecho de la Universidad de Chile. Correo electrónico: hcardenas@derecho.uchile.cl.

${ }^{1}$ Sobre la autonomía de la acción indemnizatoria en la obligación de hacer en la jurisprudencia debe verse López Díaz, Patricia (2010). "La indemnización compensatoria por incumplimiento de los contratos bilaterales como remedio autónomo en el derecho civil chileno". Revista Chilena de Derecho Privado, No 15, p. 69. La autora hace referencia al caso Transportes Aeropuerto Express Ltda. c/ LADECO S.A. 2007, en donde la Corte Suprema se pronunció sobre la existencia de un conflicto normativo entre el artículo 1489 y el artículo 1553, invocando al efecto, el principio de especialidad para resolverlo.

${ }^{2}$ Alessandri, Arturo et al. (2004). Tratado de la obligaciones. Vol. II, Santiago: Editorial Jurídica de Chile, 2a edición, p. 259. 
Técnicamente, se trata de dilucidar si en el marco conceptual de la responsabilidad contractual por el incumplimiento de una obligación de dar, la acción indemnizatoria es una acción principal y autónoma; y si, ante su incumplimiento, está facultado el acreedor para optar por la acción que más le interese.

El problema tiene importantísimos efectos prácticos pues, en términos simples, nos obliga a determinar si, ante el incumplimiento de una obligación de dar, puede el acreedor solicitar la resolución del contrato con indemnización de perjuicios; el cumplimiento del contrato también con indemnización; o única y autónomamente, la indemnización de perjuicios. Si p.e., se tratase de la entrega de un departamento, el acreedor podría elegir: a) que se le entregue el departamento (cumplimiento específico) y que se le indemnizaran los daños que el retardo le causó; b) que no se le entregue (pues opta por la resolución), se le restituyan los bienes que en concepto de pago hubiese entregado, y que se le indemnicen los daños que el incumplimiento le generó; o $c$ ) que única y autónomamente se le indemnicen los perjuicios sufridos. En todos los casos habrá que determinar si se indemnizará la afectación del interés contractual negativo (que busca restaurar la situación anterior al contrato) o la del interés contractual positivo (que es la lógica del cumplimiento). Y, en este último caso, habrá que analizar si la indemnización incluirá el valor del departamento que no se me entregó (cumplimiento en equivalente), además de otros beneficios que hubiera obtenido si se me hubiera entregado en el tiempo oportuno.

El problema debe ser abordado desde que en los últimos años un sector cada vez más influyente de la doctrina nacional ha abogado por la autonomía de la acción indemnizatoria ${ }^{3}$, y en algunos fallos recientes, la Corte Suprema se ha mostrado proclive a acoger la tesis. Así, dentro de la "serie de fallos" se suelen citar en apoyo de la tesis de la autonomía se encuentran: "Barthet con Payne 1880"; "Virgiglio con Schiavetti 1894”; "Transporte Aeropuerto Express con Ladeco 2007"; "Opazo Lamana ccon Inmunomédica Laboratorio Limitada 2010"; "Toro Fuentealba con Concha Sandoval 2012'»; "Zorin S.A con Compañia Siderúrgica

\footnotetext{
${ }^{3}$ Cfr. Vidal Olivares, Álvaro (2007). "El incumplimiento de las obligaciones con objeto fungible y los remedios del acreedor afectado: una relectura de las disposiciones del 'Código Civil' sobre incumplimiento". En: El Código Civil del Chile (1855-2005), Guzmán Brito, Alejandro (Ed.), Santiago: LexisNexis, pp. 499 y ss.

${ }^{4}$ Corte de Apelaciones de Valparaíso, "Barthet con Payne", 17 de octubre de 1867, Gaceta de los Tribunales, s/no, 1868, S. 815, pp. 354-355.

${ }^{5}$ Corte de Apelaciones de Valparaíso, "Virgiglio con Schiavetti", 15 de diciembre de 1894, Gaceta de los Tribunales, s/no, S. 3687, pp. 533-535.

${ }^{6}$ Corte Suprema, “Transporte Aeropuerto Express con Ladeco", 16 de agosto de 2007, Rol No 6042-2005, NI LegalPublishing No 38928.

${ }^{7}$ Corte Suprema, "Opazo Lamana con Inmunomédica Laboratorio Limitada", 7 de diciembre de 2010, Rol No 3341-2009. Pese a que el fallo versa sobre una obligación de hacer hay un interesante obiter dicta a cargo del Ministro Sergio Muñoz y sendas prevenciones de los Ministros Oyarzún y Araneda.

${ }^{8}$ Segundo Juzgado Civil de Chillán, “Toro Fuentealba con Concha Sandoval”, 8 de septiembre de 2009, Rol No 933-2008; Corte de Apelaciones de Chillán, 13 de enero de 2011, Rol No 438-2009; Corte Suprema, 13 de junio de 2012, Rol No 2220-2011.
} 
Huachipato 2012"; "Ampuero Asencio con Castillo Hernández 2013"10. A esta lista podríamos agregar el reciente fallo de Corte Suprema al resolver el caso "Stange Hoffman con Ripley Puerto Montt 2013"1. No obstante lo anterior, un correcto análisis de la jurisprudencia referida no puede dejar de advertir la impertinencia de la mayoría de los casos citados, en tanto que resuelven casos en donde no se presentó propiamente el problema porque se trataba de obligaciones de hacer. Así las cosas, se puede afirmar que "Zorin S.A. con Compañia Siderúrgica Huachipato 2012” es - prácticamente-, el primer caso en el que la Corte Suprema se pronuncia en favor de la autonomía de la acción, enfrentando propia y conscientemente el problema, es decir, resolviendo un caso que involucraba una obligación de $d_{a r^{12}}$.

El objetivo de este comentario es hacer una pequeña contribución al debate sobre la autonomía de la acción indemnizatoria y la eventual facultad de optar del acreedor, analizando los argumentos esgrimidos por la Corte y haciendo algunas apreciaciones respecto de los términos en que se plantea el problema. Aun así, como el sector de la doctrina que apoya la tesis de la autonomía ha propuesto una interpretación de la norma contenida en el artículo 1489 del CC que difiere de la opinión tradicional, pasaremos revista de sus argumentos, antes de referirnos propiamente a los expresados en el fallo.

\section{LOS ARGUMENTOS DE LOS PARTIDARIOS DE LA AUTONOMÍA}

El sector de la doctrina que está propiciando la existencia de un derecho del acreedor a optar por el remedio que más le convenga se basa en una serie de argumentos que van desde la exégesis del texto del 1489 hasta los efectos prácticos de las normas del juicio ejecutivo ${ }^{13}$. Siguiendo el trabajo doctrinal que ha sido citado en la jurisprudencia que admite la opción en las obligaciones de hacer ${ }^{14}$, los argumentos que apoyan la autonomía de la acción indemnizatoria ante cualquier tipo de obligación serían los siguientes:

Primero: el artículo 1489 del CC no precisa si la indemnización de perjuicio es autónoma o complementaria, advirtiéndose un vacío legal que debe ser llenado con la interpretación sistemática de los artículos 1553 (obligación de hacer), 1555

\footnotetext{
${ }^{9}$ Quinto Juzgado Civil de Santiago, “Zorin S.A con Compañía Siderúrgica Huachipato”, 30 de noviembre de 2009, Rol No 20400-2008; Corte de Apelaciones de Concepción, 11 de enero de 2012, Rol No 5332010; Corte Suprema, 31 de octubre de 2012, Rol No 3325-2012.

${ }^{10}$ Corte Suprema, "Ampuero Asencio con Castillo Hernández”, 28 de enero de 2013, Rol No 5898-2012.

${ }^{11}$ Corte Suprema, "Stange Hoffman con Ripley Puerto Montt", 2 de octubre de 2013, Rol No 8607-2012.

${ }^{12} \mathrm{El}$ otro caso en que se concedió la acción indemnizatoria tratándose de una obligación de dar es "Virgiglio con Schiavetti" (véase nota 5). La antigüedad del caso y el hecho de que la doctrina no es propiamente de Corte Suprema le restan valor a esta jurisprudencia.

${ }^{13}$ López Díaz (2010), pp. 85 y ss.

${ }^{14} \mathrm{Idem}$.
} 
(obligación de no hacer) y 1590 del Código Civil, que señala referente al pago de las obligaciones.

Segundo: existirían casos en que la indemnización de perjuicios sería el único remedio posible.

Tercero: existiría un Derecho de opción del acreedor entre los distintos remedios por incumplimiento en el CC, derecho que se obtendría básicamente de la interpretación de los citados artículos 1553 y 1555 respectivamente; y, del artículo 41.1 b) y 61.1 b) de la Convención de Viena (CV). A ello hay que agregar los efectos prácticos de las normas del juicio ejecutivo.

Cuarto: el fundamento de la indemnización es el incumplimiento del contrato y no la resolución o el cumplimiento forzoso del mismo.

Quinto: la finalidad de la indemnización es la reparación integral y, sólo se alcanzaría esta reparación integral, otorgándole a la indemnización este carácter autónomo.

En atención a la naturaleza de este trabajo, no nos detendremos a analizar cada uno de los argumentos referidos. Sin embargo, nos parece que hasta el momento se han dedicado más esfuerzos a demostrar que el texto del código no impide la solución, que a aportar razones de fondo para defender la idea de que ante el incumplimiento de la entrega de una cosa ( $p . e$., de una cosecha), se le dé la opción al acreedor de exigir la cosa o su valor. En el ámbito de compraventa internacional de mercaderías las razones son evidentes; en el contexto socioeconómico chileno, es algo que habrá que justificar.

En "Zorin S.A. con Cía. Siderúrgica Huachipato 2012", la Corte Suprema también utiliza una argumentación que podríamos denominar textual, "descubriendo" que algunos artículos habrían concebido la indemnización como parte del pago. De cualquier manera, la sentencia es importante porque introduce un argumento que hasta la fecha no se había esgrimido.

\section{Los argumentos de “Zorin S.A. con Cía. Siderúrgica HUACHIPATO 2012”}

En los hechos, la Compañía Siderurgia Huachipato S.A. concurrió ante Zorin S.A., y le ofreció en venta 1500 toneladas de rodillos de laminación dados de baja por desuso. La oferta fue aceptada por Zorin S.A. quien, según lo acordado, pagó la suma de US\$267.750 por los rodillos a Cía. Siderúrgica. El elemento determinante para la celebración del contrato fue la información proporcionada por Siderúrgica Huachipato respecto de la composición química de los rodillos pues, independiente de que se trataba de unos rodillos en desuso, la composición química de éstos era alta en Níquel.

Una vez confirmada por el vendedor, la calidad y composición de los elementos minerales de los que estaban hechos los rodillos, Zorin S.A. le vendió a la empresa norteamericana Trioriente Trade Inciso las 1500 toneladas de rodillos 
por la suma de US\$330.000. Enviadas las primeras 58 toneladas de rodillos, la empresa norteamericana les informó que la composición de los metales enviados distaba enormemente a lo que se había requerido. Zorin S.A. procedió a revisar el resto de los rodillos constatando que éstos no cumplían con las calidades ofrecidas.

\subsection{La decisión de los jueces del fondo y la casación}

Conociendo de los hechos, la jueza subrogante del 5o Juzgado Civil de Santiago condenó a la demandada a pagar, en concepto de daño emergente, lucro cesante y daño moral por afectación de la imagen, la cantidad de $\$ 906.521 .548$ de pesos chilenos. La Corte de Apelaciones de Santiago revocó el fallo en la parte que concedió el daño moral (500 millones) y la Corte Suprema lo terminó de anular advirtiendo un vicio de ultra petita puesto que el juez del fondo condenó al pago de $\$ 330.000$ dólares que, si bien era el precio del contrato que se frustró con la empresa norteamericana, no guarda relación con la utilidad del negocio $(\$ 220.000$ dólares) que fue lo que en definitiva se reclamó (cons. $3^{\circ}$ ).

\subsection{Los argumentos de la sentencia de reemplazo}

Por lo que aquí nos interesa, la doctrina del fallo fue recogida en los considerandos noveno y décimo, en los siguientes términos:

"NOVENO: Una vez establecido que efectivamente ha existido un incumplimiento del contrato, corresponde determinar si la actora ha podido ejercer la acción indemnizatoria, como lo ha hecho, prescindiendo de lo que disponen los artículos 1489 y 1826 del Código Civil, que parecen indicar que tal acción no es autónoma, sino que debe siempre ir acompañada sea de la petición de resolución contractual o bien de la exigencia de cumplimiento del contrato. Como ya lo ha resuelto esta Corte en otras oportunidades, y siguiendo una moderna tendencia doctrinal (Rol 3341-012), se estima que, en este caso, la demandante ha podido plantear su demanda de responsabilidad civil contractual, sin asociarla a la resolución del contrato, pues, la entrega material de los rodillos está cumplida y parte de ellos fueron cortados" (el énfasis es nuestro).

"DÉCIMO: Que, en todo caso, una demanda de daños y perjuicios en los términos que se han descrito, debe ser considerada como parte de lo que el vendedor debe en 'cumplimiento del contrato', de acuerdo con los términos del artículo 1489 del Código Civil. En efecto, conforme al artículo 1591 'el pago total de la deuda comprende el de los intereses e indemnizaciones que se deban'. Dado que en este juicio se pretenden indemnizaciones derivadas de un incumplimiento contractual, asociadas a una entrega imperfecta de la cosa vendida, debe entenderse que el deudor está ejerciendo una acción de cumplimiento contractual, para ser debidamente pagado por el deudor, aunque la acción esté reducida a las indemnizaciones que el actor estima que la sociedad demandada le adeuda por incumplimiento del contrato" (el énfasis es nuestro).

Como habrá apreciado el lector, la argumentación contenida en el considerando noveno respecto de la resolución del contrato no es correcta desde el punto de vista 
del derecho chileno; y la contenida en el considerando décimo, es muy discutible. Una diagramación de la argumentación nos servirá para ilustrar lo que decimos.

(T) Es razonable sostener que se puede accionar de perjuicios sin pedir la RESOLUCIÓN y sin pedir el CUMPLimiento pese a los dispuesto en el 1489 del CC.

(a.1) Porque en el caso particular la RESOLUCIÓN es improcedente.

(a.1.1)' Porque el efecto de resolver es restituir (implícito).

(a.1.2)' y solo se puede restituir si la cosa permanece inalterada (implícito).

(a.1.3) y la cosa fue cortada.

(a.1.4) Así lo ha resuelto antes la Corte (3341-012).

(a.1.5) Así lo postula una moderna tendencia doctrinal.

(a.2) Porque en el caso cuando se dice acción de indemnización, debe entenderse que se está ejerciendo una acción de cumplimiento.

(a.2.1) Porque la acción de cumplimento comprende la acción de perjuicios según el 1489.

(a.2.2) Porque según el 1591 el pago total de la deuda comprende el de los intereses $\mathrm{e}$ indemnizaciones que se deben.

(a.2.2.1) Y el artículo 1591 es aplicable al caso que tratamos.

(a.2.2.2) Porque en nuestro caso, se reclaman indemnizaciones asociadas a la entrega imperfecta de una cosa vendida.

(a.2.2.3)' y el supuesto descrito es asimilable al supuesto de hecho de la norma que regula el pago que se realiza a través la entrega de un cuerpo cierto cuando el mismo experimenta deterioros (implícito).

(a.2.3) Y es cumplimiento aunque la acción esté reducida a las indemnizaciones que el actor estima que le adeudan.

\section{CRÍtica y PROYECCIONES}

La solución final adoptada por el fallo nos parece justa, salvo en lo que dice relación con la supervivencia del contrato. Sin embargo, siendo el primer fallo que acoge la tesis de la autonomía, el mismo debe ser valorado en atención a la solidez de los argumentos más que en atención al resultado práctico conseguido. Por lo mismo, en lo que sigue comentaremos la fundamentación de la decisión tanto desde el punto de vista formal (i); como desde el punto de vista sustantivo (ii).

\subsection{Desde el punto de vista formal}

Desde el punto de vista puramente argumentativo, el fallo presenta algunas deficiencias que le impiden justificar la decisión. En efecto, la estructura argumentativa que lleva a sostener la tesis de que es razonable defender que se puede accionar autónomamente pese a los términos del 1489 del CC (T), básicamente 
se sostiene en dos argumentos o premisas ( $a .1$ y a.2), que no pueden justificarla porque son falsos o incorrectos.

En efecto, la Corte estima improcedente la resolución (a.1), porque parte de la cosa entregada fue cortada (a.1.3), lo que implica que el efecto de la resolución es restituir (a.1.1), y que solo se pueden restituir cosas que no han experimentado deterioros (a.1.2). El último de los argumentos implícitos es incorrecto, puesto que no hay normas que impidan la resolución cuando las cosas hayan experimentado deterioros y, tratándose del pago, incluso las hay que la posibilitan. Así, p. e., el artículo 1590 CC prescribe que el acreedor debe recibir la cosa con sus deterioros salvo que éstos se deban a culpa del deudor. Los argumentos coordinados (a.1.4) y (a.1.5) tampoco sirven para justificar la premisa, puesto que, en el caso del primero (asi lo ha resuelto antes la Corte [3341-012]), el rol que refiere está errado o reconduce a un caso que no tiene que ver con el tema tratado ${ }^{15}$. Respecto del segundo (así lo postula una moderna doctrina), el argumento también es débil, pues no identifica a qué doctrina se refiere.

El otro argumento propuesto por la Corte, esto es, que cuando se ejerce una acción indemnizatoria debe entenderse que se está ejerciendo una acción de cumplimiento (a.2), contraviene derechamente la tesis de la autonomía porque identifica la acción de perjuicios con la acción de cumplimiento. Aun así, la afirmación carece de justificación, porque se apoya, a su vez, en dos argumentos falsos (a.2.1 y a.2.2).

Así, cuando la Corte sostiene-sin más-que por indemnización debe entenderse cumplimiento, porque la acción de cumplimento comprende la acción de perjuicios según el 1489 (a.2.1), incurre en la clásica falacia de la petición de principio, pues el razonamiento presupone lo que debe probar: que el artículo 1489 CC no refiere tres acciones distintas cuando reza "o la resolución o el cumplimiento, con indemnización de perjuicios”. Y, cuando la Corte refiere que por indemnización debe entenderse cumplimiento, porque según el artículo 1591 el pago total de la deuda comprende el de los intereses e indemnizaciones que se deben (a.2.2) y el articulo 1591 del CC es aplicable al caso que tratamos (a.2.2.1), incorpora un nuevo argumento que tampoco se sostiene.

Lo anterior, porque para defender su nuevo argumento (aplicabilidad del artículo 1591 del (C), la Corte arguye explícitamente, que se reclaman indemnizaciones asociadas a la entrega imperfecta de una cosa vendida (a.2.2.2), e implícitamente, que los hechos acaecidos son asimilables al supuesto de hecho de la norma contenida en el 1591 del CC, que regula el pago que se realiza a través la entrega de un cuerpo cierto cuando el mismo experimenta deterioros (a.2.2.3). Básicamente, el razonamiento es incorrecto, porque realiza una falsa analogía: presupone que pago equivale a indemnizar (que es precisamente lo que debe demostrar); y no advierte que se trata de una norma que regula el pago que se realiza a través de la entrega

\footnotetext{
${ }^{15}$ Muy probablemente la Corte se refería al citado Corte Suprema, "Opazo Lamana con Inmunomédica Laboratorio Limitada”, 7 de diciembre de 2010, Rol No 3341-2009.
} 
de un cuerpo cierto y que, en el caso que estudiamos, se trataba del pago que se realiza a través de una cosa genérica (150 toneladas de rodillos de níquel).

Así las cosas, cuando menos desde el punto de vista de la estructura de la argumentación, nos parece que el fallo evidencia falencias que le impiden ser considerado como un ejemplo a seguir.

\subsection{Desde el punto de vista sustantivo}

El problema es mucho más complicado desde el punto de vista sustantivo puesto que, más allá de la literalidad de una u otra disposición, la autonomía de la acción plantea preguntas que no han sido suficientemente analizadas al interior del ordenamiento jurídico chileno. Así, entre otros aspectos, habría que determinar cuál es el modelo de cumplimiento de las obligaciones que contempla el CC; cuál es la entidad y la cuantía de las indemnizaciones que se pueden demandar en cada supuesto y; cuáles serían los límites de un eventual derecho del acreedor a elegir la acción que más convenga a sus intereses.

Respecto del cumplimiento de las obligaciones, en el derecho comparado se observan tres modelos para regular la coexistencia de las acciones. Así, por un lado, están los ordenamientos que prefieren los remedios de conducta o cumplimiento; por otro, los que prefieren los remedios monetarios y; por último, los que están por dejar al criterio del acreedor la elección del remedio que más le acomode a sus intereses. En este contexto, se ha observado, que el principio de libre elección es la solución por la que ha adoptado los PECL ${ }^{16}$ y la CV; pero en el Derecho Alemán parece existir un sesgo en favor de los remedios de conducta; y en el Derecho del Common Law de las jurisdicciones de los Estados Unidos de América se han decantado por remedios monetarios ${ }^{17}$.

\footnotetext{
${ }^{16}$ Los PECL (Principles of European Contract Law), fueron redactados por la Comisión de Derecho Europeo de los Contratos (Commisionn European Contract Law), entidad constituida entre 1980 y 1982, a solicitud de la entonces Comunidad Europea (hoy UE), por iniciativa y bajo la presidencia de Ole Lando, de la Escuela de Negocios de Copenhague, con la colaboración de Winfried Hauschild, jefe de la División en la Dirección General para el Mercado Interno de la Comisión de la ahora Unión Europea y conformada por juristas provenientes de los distintos países pertenecientes a dicha organización.

${ }^{17}$ Una referencia explícita a la primacía de la acción de cumplimiento sobre la indemnizatoria en el derecho alemán puede encontrarse en Looschelders, Dirk (2011). Schuldrecht Allgemeiner Teil. München: Vahlen, pp. 155 y 209. En los pasajes referidos, el autor sostiene que en consideración a los intereses del deudor se otorga primacía a la acción de cumplimiento en naturaleza sobre la indemnización compensatoria. Por eso, antes de ejercer la acción de indemnización de perjuicios compensatoria el acreedor tiene que otorgarle al deudor un plazo razonable para cumplir, y si dentro de ese plazo no cumple, puede pedir la indemnización. Lo anterior, siempre que todavía tenga sentido para el acreedor el cumplimiento en naturaleza; de lo contrario, puede inmediatamente solicitar indemnización, sin que sea una condición de ejercicio de la acción que se haya dado el referido plazo al deudor para cumplir (BGB\$280 en relación con \$\$281-283). Cfr. Gómez Pomar, Fernando (2007). "El incumplimiento contractual en el derecho español". InDret, 3/2007, Barcelona: Universitat Pompeu Fabra, pp. 13 y ss.
} 
La doctrina tradicional chilena, cuando menos al tratar las obligaciones de dar, reconoce una preferencia del ordenamiento por los remedios de conducta ${ }^{18}$. Lo anterior no excluye, por cierto, que en determinados casos pueda permitirse que el acreedor acceda al remedio indemnizatorio que más le convenga. Pero al ser excepcional, esta posibilidad impone al acreedor y al juzgador la carga de justificar que se trata de un caso especial, y nos obliga a reflexionar sobre los límites que se deben poner, para evitar que el resultado de la opción sea excesivamente gravoso para el obligado. Ahora bien, una vez fuera de la lógica de la preferencia por los remedios conductuales, ya no se ve tan claro por qué conceder una facultad de opción al acreedor y no decantarnos derechamente por los remedios monetarios como lo hacen algunas jurisdicciones del Common Law.

En relación a la naturaleza y la cuantía de las indemnizaciones que se solicitaron, la aceptación de la tesis de la autonomía plantea espinosos interrogantes que tan solo podemos enunciar aquí. Así, habrá que determinar si la indemnización incluirá el valor de la prestación no realizada, además de las de ganancias que esperaba obtener, y de otros eventuales daños que se puedan conectar con el incumplimiento. Todo ello tendrá importancia para analizar el efecto que esta indemnización tendrá sobre la vida del contrato, y sobre el régimen que se aplicará para ejecutar la misma.

En el caso que se analiza, pese a que se había pedido que se devolviera el adelanto del precio que se había pagado ( 25 millones), la Corte solo concedió la indemnización por la ganancia que se dejó de obtener al frustrarse el negocio (114 millones en concepto de lucro cesante). Resulta interesante que, al negarse a "indemnizar" la parte del precio que se había pagado, la Corte manifestó: "que el demandante no ha pedido la resolución del contrato, que sería la única causa para exigir este dinero a titulo restitutorio. De la manera que se ha demandado ha quedado el contrato subsistente y el demandado tiene derecho a mantener los rodillos en su poder". De la doctrina del fallo, se pueden extraer al menos dos conclusiones: así, por un lado, se puede decir que en Chile se debe resolver el contrato si se quiere pedir de vuelta la prestación realizada; y, por otro, que la indemnización de las expectativas de ganancia puede ser pedida sin exigir el cumplimiento del contrato que, por lo mismo, queda vivo y podría eventualmente exigirse su cumplimiento. A nuestro juicio, esto último nos pone frente al problema del enriquecimiento sin causa, puesto que parece tener una ventaja injustificada quien, habiendo ya obtenido la ganancia que le hubiera reportado la venta de la cosa, puede todavía exigir la entrega de la cosa ${ }^{19}$.

\footnotetext{
${ }^{18}$ Cfr. Abeliuk Manasevich, René (2008). Las obligaciones. Tomo II, Santiago: Editorial Jurídica de Chile, 5a Edición, 2008, pp. 812 y ss. BARros Bourie, Enrique (2007). "La diferencia entre 'estar obligado' y 'ser responsable". En: Estudios de Derecho Civil II, Jornadas Nacionales de Derecho Civil Olmué 2006, Santiago: LexisNexis, p. 751. cumplimiento específico frente al incumplimiento contractual". En: Incumplimiento contractual. Nuevas perspectivas, Cuadernos de análisis jurídico, Colección derecho privado VII, Santiago: Universidad Diego Portales, pp. 235-262.

${ }^{19}$ Cfr. Abeliuk Manasevich (2008), p. 813.
} 
El caso parece haberse resuelto de acuerdo al régimen de responsabilidad contenido en los PECL y la CV (principio de libre elección) y, por lo mismo, su fundamentación sobre la base de una normativa que "prefiere" el remedio conductual (pago), luce muy artificiosa. Adicionalmente, la comprensión que concibe la indemnización de perjuicios como parte del pago contraviene la idea de una acción de perjuicios autónoma, y no guarda relación con el concepto de responsabilidad contractual que ha venido decantando en los últimos años. Y es que, como el mismo FrIED ha admitido, hay cosas que se dan a título de indemnizaciones que no pueden explicarse desde el contrato ${ }^{20}$.

De cualquier manera, el hecho de que no estemos de acuerdo con la vía argumentativa que utilizó el fallo (artículo 1591 del CC.) no implica que no estemos de acuerdo con la autonomía de la acción de perjuicios. Dotar de autonomía a la acción indemnizatoria nos parece deseable desde la perspectiva del sistema de daños, y nos parece que el fallo es un aporte por cuanto obliga a la doctrina a continuar con el estudio de las relaciones entre los diferentes remedios, así como de otros importantes problemas como el de la primacía o la exhaustividad de los mismos.

\footnotetext{
${ }^{20}$ Atryah, Patrick (1981). "Book review of Charles Fried, Contract as promise". Harvard Law Review, Vol. 95, pp. 515-528. También véase FrIED, Charles (1981). Contract as promise: a theory of contractual obligation. Boston: Harvard University Press.
} 